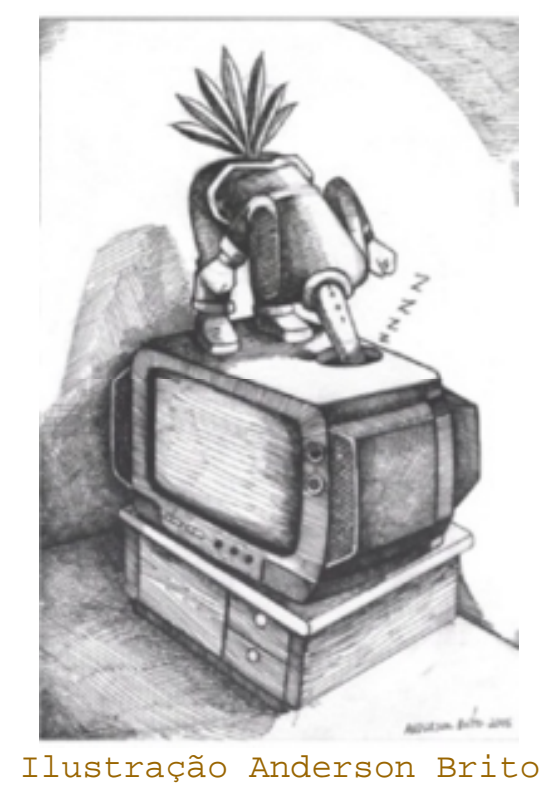

\title{
Corpo, sujeito e experiência: rede telemática, TV e leitura
}

\section{Alemar Rena}

Alemar Rena é mestrando da Faculdade de Letras/UFMG e professor da Unileste/MG.

\section{Resumo}

O presente artigo investiga a experiência do sujeito perante as telas e os textos verbais. É dada ênfase aos meios TV, rede telemática e livro, embora eventualmente se aborde também o jornal impresso e o rádio. Argumenta-se que o limite entre real e virtual é mais complexo (senão impossível) de ser apontado do que parece, pois diante dos meios virtualizadores nos encontramos em um entre-lugar. Discute-se ainda a identidade do sujeito perante os meios, sugerindo estar aí o cerne da questão sobre o que os meios virtuais significam, do ponto de vista social e político, para o homem contemporâneo.

Palavras-chave: meios, experiência, identidade.

\section{O real: um entre-lugar}

Ouvimos comumente falar de experiências que envolvem ou não o corpo, criando-se dois níveis distintos e não intercambiáveis de experiência; mas toda experiência envolve fisicamente o corpo, ou seja, uma experiência incitada, mesmo que por um aparelho eletrônico que oferece algum tipo de informação 
virtual, interfere sempre no corpo-carne. Este pensamento é análogo ao oferecido por paul Zumthor(1) ao sugerir que o ato de leitura não é de forma alguma apenas uma ação intelectual, mas, pelo contrário, extremamente corporal. Tal avaliação pode ser estendida aos outros meios.

Da mesma forma, o teórico Maxine Sheets-Johnstone, ao advogar um olhar holístico para o estudo do corpo, pergunta:

\begin{abstract}
Como a mente se relaciona com o corpo físico? Como, no dia-a-dia, os dois interagem para formar uma união? Tendo em vista o universo metafísico com o qual as pessoas normalmente convivem, é irônico que uma separação, em vez de uma unidade, seja prontamente aceita como metafisicamente seguro. A interação é o problema a ser pensado, assim como foi para Descartes, a quem se atribui o desenvolvimento do conceito original da separação(2). (tradução minha)
\end{abstract}

Gumbrecht lança alguma luz sobre a questão ao dizer que "O 'pensamento moderno' (...) viu-se, singularmente, ao mesmo tempo separado do corpo humano e ligado a ele. Essa dupla relação entre pensamento e corpo está co-articulada no conceito de sujeito."(3) Ele afirma que a relação entre mente e corpo se realiza na dimensão do espaço, "Pois toda experiência atual ou toda intervenção agente está sempre dividida em zonas espaciais - por exemplo, no 'mundo ao alcance real', no 'mundo ao alcance potencial' e no 'mundo fora do alcance potencial""(4). Aí, o mundo do virtual seria aquele "fora do alcance potencial", ou seja, do alcance físico. A pergunta seria como o corpo se interage com o espaço nesse "fora do alcance potencial".

Não devemos pensar o corpo biologicamente? A experiência não passa, antes de tudo, por um desencadeamento de sensações físicas que agem dentro da mente, se tornando assim a própria mente? Não soa um tanto preconceituosa a asserção de que a experiência virtual, apenas por ser tal coisa, é mais pobre do que a experiência real?

Nosso corpo possui cinco sentidos: olfato, tato, visão, audição e paladar. Ao nos interagirmos com a grande maioria dos meios eletrônicos hoje utilizamos apenas dois deles: a audição e a visão. Assim como um dia a TV ampliou as possibilidades sensitivas em relação ao meio "rádio", que se utilizava apenas da audição, os meios eletrônicos diminuem as possibilidades físicas biológicas comparativamente à percepção no mundo real, onde normalmente os cinco sentidos estão em ação. Podemos dizer que a experiência mediada por aparatos eletrônicos como o rádio, a TV e a rede telemática é limitada a menos sentidos, portanto diferente. 
O computador, embora ainda limitado, recupera o tato ao nos oferecer um teclado e mouse nos quais pegamos, movemos e sentimos "tocar" na tela. Quando usamos demasiadamente essa interface, às vezes importamos alguns movimentos para o mundo real, fora da tela: exemplo seria procurarmos a tecla "delete" para tentarmos apagar um texto escrito a lápis no papel. Inversamente, os desenvolvedores de interfaces gráficas para o computador procuram sempre "humanizar" nossa relação com a máquina ao levar para a tela ícones e procedimentos que nos aproximam do nosso dia-a-dia no mundo real.

O computador exige que nos movamos fisicamente, que toquemos, que editemos, que falemos, que tomemos decisões, que, em suma, troquemos ações em vários níveis distintos. Novas tecnologias que atualmente vêm sendo desenvolvidas apontam para um engajamento global dos sentidos na interação com as máquinas nos processos de cognição, criação e nas tele-comunicações, o que torna mais difícil pensarmos a relação corpo-máquina pela dicotomia real-virtual; em vez disso, não devemos entender esse encontro como um processo de hibridização do corpo, em um fluxo constante entre a vida "à base de carbono" e os "corpos sintéticos de silício"(5)?

Mas, se na experiência homem-máquina, integrados digitalmente, temos um ambiente híbrido, onde o real e o virtual se encontram dando lugar a um "estar entre", não podemos deixar de notar diferenças entre essa experiência "hibridizada" e a vivência não mediada no mundo real, despido das telas. A experiência de acesso a informação pela TV, por exemplo, difere do real não somente no número de sentidos biológicos em jogo, mas na própria ordem do sentido, pelo simples fato de ser virtual. Assim, não podemos dizer que temos a mesma experiência quando assistimos a um assassinato em um noticiário e o vivenciamos na vida real não mediada. Existe um estar presente do corpo no "mundo ao alcance potencial" que torna a experiência diferente daquela no "mundo fora do alcance potencial".

Nosso corpo entende que ao experienciarmos um assassinato pela tela não corremos perigo (e a noção de perigo está fortemente enraizada nos nossos instintos e diluída na nossa experiência no mundo). Mas o fato de não sentirmos perigo (podemos, dependendo do contexto, sentir um certo perigo indireto, mas bem menos intenso) na situação acima não demonstra ser nula a possibilidade de sentirmos perigo em frente a uma tela. Dentro do computador pessoal está parte de nosso mundo, informações pessoais, nele nos movemos e agimos, tomamos decisões; estamos, em certa medida, presentes e vulneráveis, como no mundo real. 
Mas apenas por isso, pelo fato de não haver uma dimensão física da presença, não se pode dizer que as experiências virtuais são sempre mais pobres, uma vez que seria legítimo argumentar que na virtualidade, por exemplo, da rede telemática há uma gama de possibilidades compensatórias: a interação e edição da informação acessada; a superação de barreiras geográficas; a flexibilidade da comunicação pela combinação de elementos representacionais como a imagem, o som e a palavra; a maleabilidade da identidade (da qual tratarei mais abaixol do produtor e receptor, etc. A respeito da virtualidade televisiva, Gumbrecht sugere:

O argumento segundo o qual uma ida ao estádio jamais poderia atingir a pletora de detalhes e a visão geral da 'cobertura esportiva' possibilitada pela televisão se torna cada dia mais forte e convincente. Será que finalmente encontramos o meio-termo ideal entre o afastamento do corpo e as formas de compensá-lo?(6)

São exatamente nessas formas de compensação que a virtualidade ganha sentido perante o mundo real.

Por outro lado, como disse anteriormente, estaria cometendo um equívoco se tentasse, generalizadamente, enquadrar toda experiência na dicotomia virtual/real. Hoje, principalmente devido à possibilidade de intensa interação homem-máquina que - computador proporciona, devemos, mais do que antes, pensarmos a experiência com base em um conceito de realidade mista em que, "conectados, (...) estamos em estados de passagem, num trânsito de alguma coisa para outra coisa estranha e diferente". O real não estaria nesse "intervalo, em uma instância elíptica"(7)?

Pois na World Wide Web (WWW) não somente temos acesso à informação, mas contribuímos para sua edificação por inputs de inúmeras ordens; o computador promove "uma total recuperação do controle sobre a tela de modo que (...) compartilhamos a responsabilidade de produzir significado. Produzimos significados junto à máquina e as pessoas"(8). Ao dizer, como disse anteriormente, que pelo computador pessoal estamos vulneráveis, estou assumindo que discutir o limiar entre 0 real e o virtual faz pouco sentido, pois uma realidade se integra à outra e vice-versa, construindo uma única vivência complexa.

\section{A experiência pela linguagem e o comportamento do sujeito}

No jogo comunicacional, o meio, que se apóia na linguagem para oferecer informação, estabelece uma íntima relação com nossa mente, definindo sensivelmente como vivemos e quem somos. Podemos assentar essa asserção em um nível tão fundamental quanto possível: a teoria da evolução, de Darwin, discutida por Maxine Sheets-Johnstone: 
Hominídeos ancestrais, dos quais herdamos descobertas e práticas, não eram humanos. Se eles não pensavam, como é possível que nós o fazemos? (...) Dadas as evidências compreensíveis para a evolução orgânica, a resposta mais provável é que o pensar se desenvolveu lado a lado com o fazer (o que quer dizer que a experiência se desenvolveu lado a lado com o comportamento) e que não foi nem mero acaso nem, de maneira alguma, um desenvolvimento evolucionário biologicamente separado.(9) (tradução minha)

A colocação de Sheets-Johnstone sustenta a tese de que historicamente o ato de pensar evoluiu com o ato de fazer, ou melhor, o meio no qual vivemos e a experiência que dele retiramos de certa forma modela a forma de pensar e, não menos verdade, nosso comportamento. Para percebemos a utilidade dessa colocação para a presente discussão, temos, a princípio, que pensar a relação entre a linguagem de comunicação que os meios nos oferecem e a experiência de seus usuários para podermos, posteriormente, identificar uma possível relação entre a experiência pela linguagem e o comportamento do usuário do meio.

Kerckhove nos ajuda a entender como a linguagem do meio pode interferir no comportamento. Para o autor, a finalidade do anúncio de televisão é nos manter num modo receptivo, não crítico. Quando assistimos à $T V$, somos confrontados com questões que não temos tempo de responder. A partir dessa impossibilidade de "digestão" do conteúdo, a TV constrói uma "mentalidade coletiva" composta por espectadores abertos à "doutrinação comercial"(10) .

Há, segundo o pensamento acima, algo na estrutura da veiculação da informação pela TV que induz um certo tipo de percepção da informação, e que, por conseqüência, modela a maneira como o telespectador pensa e se comporta em relação ao mundo. A TV não nos dá tempo para pensarmos sobre as verdades (incluindo-se aqui os comerciais) que ela mostra; não nos oferece tempo para nem mesmo levantarmos questões que nossa vivência cotidiana exige que levantemos para que decidamos o que é melhor ou pior para nossa experiência no mundo, ou, no caso, a experiência na frente da tela. Assim, ao contato intensivo com tal meio, passamos a agir colocando em prática um tipo de racionalidade (no caso da TV, rápida e superficial) que o próprio meio nos ensinou. O exemplo de Kerckhove corrobora a tese de Sheets-Johnstone.

A interferência na temporalidade e na natureza de nossa percepção levada a cabo pela exposição massiva à TV (mas não somente a ela) produziu seus efeitos na própria cultura da leitura, à medida que novas gerações, habituadas à recémnascida velocidade do meio televisivo, se sentem pouco 
operantes frente ao texto escrito, que exige de suas capacidades sensoriais um outro tempo, o da leitura verbal. Grande parte dos jovens hoje sentem dificuldade em lidar com esse outro tempo; quando, no caso da comunicação por mensagens digitais como o e-mail e os chats, se exige desses jovens interlocutores a comunicação pelo texto escrito, o que se tem é uma produção verbo-textual fortemente atravessada pelas velocidades da $T V$, resultando em textos pequenos, gramaticalmente distantes das normas da língua padrão e muito mais próximos da linguagem oral e visual (acompanhados de ícones vetoriais e imagens do tipo bitmap).

Por um raciocínio similar, podemos afirmar sem relutância que a vivência na WWW, ambiente extremamente efêmero, lugar de espaços pouco reiteráveis, induz seus usuários a refletir sua estrutura fractal, abrindo espaço para fortes processos de esfacelamento das identidades.

o espaço virtual, cibernético e interativo estimula uma certa refração do eu, rendendo aos interagentes subjetividades sempre mais fragmentárias e múltiplas. Ao contrário do mundo real, na rede telemática pouco importa quem sou, desde que eu satisfaça as necessidades do virtual: esteja conectado, esteja extraindo prazer e/ou possa ser útil a meus objetivos e/ou a meu interagente. Noções como classe, localização física, círculo de amizades, aparência física, etc. pouco importam(11).

Portanto, posso apresentar ou representar a identidade que mais me agrada ou me é útil em determinada situação, uma vez que não há, em relação aos interlocutores virtuais, uma imagem clara, suplantada por referências do mundo real.

Como nos vai falar Hans-Georg Gadamer, estes discursos da WWW se apóiam em uma certa anonimidade muito distinta daquela anonimidade que perpassa a mídia de massa como um todo(12). Pois para os meios chamados um para todos, como a TV, o rádio ou o jornal, a anonimidade se encontra muito mais do lado do espectador do que do enunciador. Ou seja, sabe-se relativamente bem quem fala (embora estejamos cientes da complexidade destes discursos), mas se desconhece (a não ser através da idéia de massa, como se faz através de pesquisas com grupos amplos de espectadores) quem ouve ou assiste. Pierre Lévy afirma que "a verdadeira ruptura com a pragmática da comunicação instaurada pela escrita não pode estar em cena com o rádio ou a televisão, já que estes instrumentos de difusão em massa não permitem nenhuma verdadeira reciprocidade nem interações transversais entre participantes. (13)

Neste sentido, podemos aproximar, mais do que afastar, o meio livro de meios como o rádio e a televisão, pois ambos estão 
inseridos em um mesmo modelo de comunicação em que o autor do discurso é predeterminado enquanto o interlocutor interagente é desconhecido.

Por contraste, o ciberespaço estabelece um novo modelo comunicacional composto de novos discursos em que ambos os interagentes podem estar em contato direto, produzindo trocas constantes:

O indivíduo foi criado pela leitura e pela escrita com o alfabeto; - coletivo foi criado pelo rádio e pela televisão. Nós estamos desenvolvendo em âmbito mundial um novo tipo de mente que vai bem além do coletivo. É a mente conectiva (...) em que podemos cultivar e manter uma identidade privada, mas também compartilhar - processamento de informações com um grupo seleto sem sermos eliminados pela identidade do grupo.(14)

É apenas dando voz a todos os interlocutores envolvidos no processo, em "interações transversais", que se pode sustentar a identidade privada autônoma em detrimento da identidade coletiva fixa.

Paradoxalmente, se por um lado o ciberespaço permite as "interações transversais entre participantes" em um contexto imediato no qual os interagentes se "tocam" e se apresentam um ao outro, por outro lado, em um contexto mais amplo, ele ataca a estabilidade da figura de quem produz um discurso, e uma das justificativas para tanto é justamente a facilidade de acesso direto aos produtores e espectadores, ou seja, quanto mais fácil é para todos falarem, menos força tem cada discurso. Esses são os discursos "da democracia, da cidade grande, das administrações, da cibernética (grifo meu). Trata-se de uma multidão móvel e contínua, (...) que perdem nomes e rostos...", nos diz Michel de Certeau(15).

Estes discursos não contam com o apoio restrito (portanto excludente) das instituições que, no contexto dos meios umpara-todos, lhes garantiria a estabilidade através da "seleção" e "delimitação", como bem esclarece Foucault(16). o que se tem é um tipo específico de anonimidade, diferente daquela que a TV, o rádio ou o jornal impresso produzem, que afeta todos os participantes da rede ao mesmo tempo, e não apenas os espectadores.

\section{A experiência pelos meios, cultura e sociedade}

Gumbrecht vai dizer, sobre a pós-modernidade, que "o horizonte de expectativa permanece ocupado pelo cenário de um fim causado pelos homens - da humanidade ou do planeta". Para ele "não é possível esquecer ou destruir esse saber tecnológico cuja utilização significa o fim de toda a vida sobre a terra." (17) 
Tal afirmação nos obriga a pensar sobre qual papel a tecnologia teria para a humanidade. Existe hoje, obviamente, esta voz catastrófica que opõe a existência da máquina à existência humana.

Existe ainda uma outra voz filosófica ingênua que crê na salvação pela máquina, principalmente através do espaço cibernético. Gadamer sugere(18), e concordo com ele, que ninguém sabe $\circ$ que a interferência dos meios eletrônicos representará para nossa sociedade a longo prazo. Qualquer discurso que sugira a catástrofe ou a salvação pelos meios eletrônicos deve ser olhado com desconfiança. Ele diz ainda: "informação vem sendo bombeada em nossas vidas em níveis inimagináveis; mas esse fluxo de informação precisa ser canalizado de maneira que não destrua nossa cultura, a cultura animi, a cultura da alma e mente humana, mas sim a alimente." (19)

O filósofo se apóia na cultura para chegar a um pensamento sobre o que os meios de comunicação de massa e a tecnologia a eles atrelada representam para a sociedade contemporânea. Para ele, importa a interferência dos meios na formação cultural da humanidade. O que "cultivamos" enquanto sociedade está intrinsecamente ligado à produção tecnológica e à forma como nos comunicamos. Tendo em vista essa colocação, nossa sociedade se confronta com um enorme desafio: a formação cultural é um processo que não é, mas está a se fazer, e que, justamente por causa desse acontecer aos poucos e enquanto vivemos, está no limiar de nossa capacidade de afastamento, reflexão e controle; como podemos pensar e agir em relação à tecnologia e as mudanças culturais que ela desencadeia? Como conciliar filosoficamente, mas mais ainda, pragmaticamente, aquilo que tem um mecanismo próprio de desenvolvimento, aquilo que de tão sutil se torna quase invisível para nossos sentidos, com aquilo em que podemos, até certo ponto, intervir mais efetivamente, ou seja: o desenvolvimento tecnológico?

Gadamer lança uma luz ao buscar, no desenvolvimento do alfabeto e da escrita, um paralelo histórico do desafio que nos é colocado. Também com a escrita, que demandou "um profundo domínio da abstração e gerou uma distância desumana de tudo que era representacional nas nossas formas de comunicação"(20), o homem esteve diante de um cenário de mudanças radicais na forma como a informação era acessada, gravada (com os manuscritos e, posteriormente, a imprensa) e transportada.

Mas se o processo de assimilação e aceitação da prática da escrita e da leitura nos deixou uma herança pela qual devemos ser gratos, (segundo o autor, teria sido graças aos poetas que histórias de mitos, deuses e heróis puderam ser trazidas à luz 
do entendimento e da humanização; Homero e Hesíodo representariam, hoje, no legado de sua tradição épica, o início da cultura ocidental centrada na elucidação racional de nossa experiência no mundo e de nossa existência(21)), é importante notar, entretanto, que todo o processo de construção de uma racionalidade e tradição edificada tendo como base o alfabeto levou milênios. A história dos meios de massa em si tem menos de cem anos, e este dado faz diferença. A partir da análise que traça, Gadamer deixa claro que o alfabeto (que não deixa de ser uma técnica que resultou em uma certa "tecnologia" de produção de sentidos), assim como a mídia de massa hoje, deixou profundas transformações no decorrer de seu desenvolvimento e uso, e, no entanto, a humanidade não ficou pior.

Para Gadamer, o problema parece estar no meio que, por sua própria lógica, nos induz à redução do acesso à comunicação (na medida em que um dos interagentes não tem voz que alcance as massas) e amplia planetariamente o alcance das informações produzidas por poucos; ele toca no cerne da problemática mídia de massa-sociedade-cultura: "a mídia de massa possui um aparato de mediatização de alcance e complexidade infinitos; assim, a imediatidade do julgamento e do ato de comunicação espontâneos é constantemente ameaçada"(22) (tradução minha). o filósofo propõe a substituição da massificação pela gestação de uma sociedade onde o poder resida no "pensamento independente e no julgamento individual"(23).

Walter Benjamin já advogava, na primeira metade do século que passou, que as massas deveriam se apropriar da arte de se fazer cinema, pois, para ele, o capital da indústria cinematográfica, assim como o fascismo, explorava, "secretamente, no interesse de uma minoria de proprietários, a inquebrantável aspiração por novas condições sociais."(24) Para nossa infelicidade, se as massas, principalmente com a intensa difusão dos meios um-para-todos após a segunda guerra, passaram a novas condições sociais, estas condições não nos parece hoje mais favoráveis e muito menos vieram das aspirações do homem comum. Há, entre os cidadãos das metrópoles contemporâneas, um sentimento de liberdade raro na história do ocidente; no entanto, esse sentimento vem acompanhado de uma apenas aparente liberdade de pensamento independente, uma vez que os grandes meios de comunicação, entre outros poderes, induzem ou, no mínimo, interferem constantemente nas decisões individuais dos espectadores.

Mas talvez o ciclo ainda não tenha se fechado; talvez ainda não tenhamos tido tempo de dizer que os desejos de Benjamin foram em vão. Quando Kerckhove fala de uma crescente coletivização das massas pelas mídias um-para-todos, com suas ferramentas para nos manter num modo receptivo, não crítico, o 
tempo todo em aberto, ele também sugere um antídoto em potencial: a comunicação em rede, que tem o poder de resgatar algo que havia se perdido: a possibilidade de "fechamento", ou seja, de termos tempo para responder ao conteúdo que nós escolhemos acessar.

Parece-me este ser um momento decisivo e histórico para a sociedade, umas vez que a rede telemática vem, paulatinamente, ganhando espaço frente aos outros meios. Dados da Online Publishers Association mostram que hoje um jovem americano de idade entre 18 e 34 prefere navegar na Internet (46\%), a assistir a TV (35\%), ler um livro (7\%), ligar o rádio (3\%), ler um jornal (3\%) ou folhear uma revista (menos de 1\%).

Embora alguns afirmem que "as redes de informação ocupariam lugar de novo vínculo social e de ferramentas para uma nova 'democracia eletrônica', direta, interativa e instantânea"(25) , com efeito esta "teologia" da rede "vai de encontro à dos empresários que vêem ali um 'mercado' para um comércio eletrônico ao mesmo tempo mundializado, personalizado e acessível a domicílio."(26) Mas a coletivização não faz parte dos processos de esfacelamento e reconstrução contínua, organizando, estabilizando e neutralizando as multiplicidades que insistem em se fazer existir? O sentimento de coletividade em si não é nocivo e pode ser, pelo contrário, necessário para a experiência positiva da vida. Neste âmbito se encontra, para Zigmunt Bauman, a principal contradição da "modernidade fluida", um "abismo que se abre entre o direito de autoafirmação e a capacidade de controlar as situações sociais que podem tornar essa auto-afirmação algo factível ou irrealista"(27). O indivíduo contemporâneo tem liberdade e autonomia para experimentar, mas até que ponto essa liberdade - leva à satisfação de seus desejos e a sua felicidade? É justamente essa contradição que Bauman, assim como Gadamer, propõe que aprendamos a manejar "coletivamente" mas não "coletivizados".

Mas onde está a resposta para a garantia do pensamento independente e julgamento individual aos indivíduos? A princípio parece que uma sociedade que faz uso exclusivo dos meios hegemônicos de comunicação de massa que temos hoje, ou seja, os meios um-para-todos, está fadada ao fracasso ao difundir uma cruel coletivização, dominação intelectual, injustiça e obliteração das vontades individuais. Parece também, perante o vertiginoso crescimento do interesse pela comunicação em rede, que a própria sociedade esteja respondendo a essa incongruência política e social.

É possível que todo o pensamento filosófico sobre as mudanças pelas quais a humanidade tem passado no último século e no presente não dê conta (ou perca força perante o poder dos 
discursos massificadores) de oferecer caminhos em direção a uma sociedade pautada em modos de uso da tecnologia que a conduza à liberdade em vez da alienação e escravização maquínica. Para pensadores como Gumbrecht, frente à "insuficiência (...) de nossos conceitos (...) filosóficos no caso da apreensão dos mundos cotidianos contemporâneos"(28), nos é urgente uma "resposta à pergunta sobre as conseqüências do deslocamento pós-moderno de espaços e tempos."(29) Enquanto - autor olha para a mídia (e para o passado) como metáfora ao mesmo tempo que causa desta mudança, sugiro aqui pensarmos, olhando para o futuro, como os novos meios de comunicação em redes podem ser atualizados e apresentados como uma possível "remissão" da tecnologia frente à sociedade.

\section{Abstract}

The present essay looks at the subject's experience before the screens and verbal texts. Emphasis is given on TV, Internet and book, although radio and newspaper are also approached. It is argued here that the limits between reality and virtuality are more complex (if not impossible) to be pointed out than it normally seems to be, for before the virtualizing media we find ourselves in between. The identity of the subject before the media is also discussed; it is suggested that this discussion is crucial for an understanding of what the media might mean for contemporary man from the social and political points of view.

Key-words: media, experience, identity.

\section{Notas}

(1) ZUMTHOR, 2000 .

(2) SheEtS-Johnstone, Maxine. Darwin Bodies: Against Institutionalized Metaphisical Dualism. In: O'DONOVAN- ANDERSON, Michael. The incorporated self: interdisciplinary perspectives on embodiment. New York: Rowman \& Littlefield, 1996, p. 13.

(3) GUMBRECHT, Hans Ulrich. Modernização dos sentidos. Tradução de Lawrence Flores Pereira, 1a edição, São Paulo: 34, 1998, p. 276.

(4) Ibidem, p. 276-277.

(5) Domingues, Diana. Criação e interatividade na ciberarte. São Paulo: Experimento, 2002 , p. 37.

(6) GUMBRECHT, Hans Ulrich. Corpo e forma: ensaios para uma crítica não hermenêutica. Tradução de Heloisa Toller Gomes, João Cezar de Castro Rocha e Johannes Kretschmer, Rio de Janeiro: UERJ, 1998, p. 134.

(7) Domingues, Diana. Criação e interatividade na ciberarte. São Paulo: Experimento, 2002 , p. 39.

(8) KERCKHOVE, Derrick de. A arquitetura da inteligência: interfaces do corpo, da mente e do mundo. In: Arte e vida no séc. XXI: tecnologia, ciência e criatividade. Tradução de Flávia Gisele saretta, São Paulo: UNESP, 2003, p. 18 . 
(9) SHEETS-JOHNSTONE, Maxine. Darwin Bodies: Against Institutionalized Metaphisical Dualism. In: O'DONOVAN- ANDERSON, Michael. The incorporated self: interdisciplinary perspectives on embodiment. New York: Rowman \& Littlefield, 1996, p. 19.

(10) KERCKHOVE, Derrick de. A arquitetura da inteligência: interfaces do corpo, da mente e do mundo. In: Arte e vida no séc. XXI: tecnologia, ciência e criatividade. Tradução de Flávia Gisele saretta, São Paulo: UNESP, 2003, p. 20 .

(11) Ver MITCHEL, William J. City of bits: space, place, and the infobahn. Cambridge: The MIT Press, 2000, p. 10 .

(12) Ver GADAMER, Hans-Georg. Culture and media. In: Cultural-political interventions in the unfinished project of enlightenment. London: MIT, 1992 , p. 173 .

(13) LÉVY, Pierre. Cibercultura. Tradução de Carlos Irineu da Costa, São Paulo, 34, 1999, p. 117 .

(14) KERCKHOVE, Derrick de. A arquitetura da inteligência: interfaces do corpo, da mente e do mundo. In: Arte e vida no séc. XXI: tecnologia, ciência e criatividade. Tradução de Flávia Gisele saretta, São Paulo: UNESP, 2003, p. 26.

(15) CERTEAU, Michel de. A invenção do cotidiano. Tradução de Ephraim Ferreira Alves, 9a edição, Petrópolis: Vozes, 1994, p. 58.

(16) Ver FOUCAULT, Michel. Estética: literatura e pintura, música e cinema Vol. III. Tradução de Inês Autran Dourado Barbosa, 1a edição, Rio de Janeiro: Forense Universitária, 2001, p. 279.

(17) GUMBRECHT, Hans Ulrich. Modernização dos sentidos. Tradução de Lawrence Flores Pereira, la edição, São Paulo: 34, 1998, p. 285.

(18) GADAMER, Hans-Georg. Culture and media. In: Cultural-political interventions in the unfinished project of enlightenment. London: MIT, 1992 , p. 177 .

(19) Ibidem, p. 176-177.

(20) GADAMER, Hans-Georg. Culture and media. In: Cultural-political interventions in the unfinished project of enlightenment. London: MIT, 1992 , p. 177 .

(21) Ibidem, p. 178

(22) GADAMER, Hans-Georg. Culture and media. In: Cultural-political interventions in the unfinished project of enlightenment. London: MIT, 1992 , p. 184 .

(23) Ibidem, p. 185.

(24) BENJAMIN, Walter. Obras escolhidas: magia e técnica, arte e política. Tradução de Sergio Paulo Rouanet, la edição, São Paulo: Brasiliense, 1994, p. 185 .

(25) MUSSO, Pierre. A filosofia da rede. In: Tramas da rede. Tradução de Marcos Homrich Hickman, Porto Alegre: Sulina, 2004, p. 35. 
(26) Ibidem.

(27) BAUMAN, Zigmunt. Modernidade Líquida. Tradução de Plínio Dentzien, Rio de Janeiro: Jorge Zahar, 2001, p. 47.

(28) GUMBRECHT, Hans Ulrich. Modernização dos sentidos. Tradução de Lawrence Flores Pereira, la edição, São Paulo: 34, 1998, p. 289.

(29) Ibidem, p. 290.

\section{Bibliografia}

ZUMTHOR, Paul. Performance, recepção, leitura. Tradução de Jerusa Pires Ferreira e Suely Fenerich, São Paulo: Educ, 2000.

SHEETS-JOHNSTONE, Maxine. Darwin Bodies: against institutionalized metaphisical dualism. In: O'DONOVAN-ANDERSON, Michael. The incorporated self: interdisciplinary perspectives on embodiment. New York: Rowman \& Littlefield, 1996, p. 13.

GUMBRECHT, Hans Ulrich. Modernização dos sentidos. Tradução de Lawrence Flores Pereira, la edição, São Paulo: 34, 1998, p. 276. Ibidem, p. 276-277.

DOMINGUES, Diana. Criação e interatividade na ciberarte. São Paulo: Experimento, 2002, p. 37 .

GUMBRECHT, Hans Ulrich. Corpo e forma: ensaios para uma crítica não hermenêutica. Tradução de Heloisa Toller Gomes, João Cezar de Castro Rocha e Johannes Kretschmer, Rio de Janeiro: UERJ, 1998, p. 134.

DOMINGUES, Diana. Criação e interatividade na ciberarte. São Paulo: Experimento, 2002, p. 39 .

KERCKHOVE, Derrick de. A arquitetura da inteligência: interfaces do corpo, da mente e do mundo. In: Arte e vida no séc. XXI: tecnologia, ciência e criatividade. Tradução de Flávia Gisele Saretta, São Paulo: UNESP, 2003, p. 18 .

SHEETS-JOHNSTONE, Maxine. Darwin Bodies: against institutionalized metaphisical dualism. In: O'DONOVAN-ANDERSON, Michael. The incorporated self: interdisciplinary perspectives on embodiment. New York: Rowman \& Littlefield, 1996, p. 19.

KERCKHOVE, Derrick de. A arquitetura da inteligência: interfaces do corpo, da mente e do mundo. In: Arte e vida no séc. XXI: tecnologia, ciência e criatividade. Tradução de Flávia Gisele Saretta, São Paulo: UNESP, 2003, p. 20 .

Ver MITCHEL, William J. City of bits: space, place, and the infobahn. Cambridge: The MIT Press, 2000, p. 10.

Ver GADAMER, Hans-Georg. Culture and media. In: Cultural-political interventions in the unfinished project of enlightenment. London: MIT, 1992 , p. 173 . 
LÉVY, Pierre. Cibercultura. Tradução de Carlos Irineu da Costa, São Paulo, 34,1999, p. 117.

KERCKHOVE, Derrick de. A arquitetura da inteligência: interfaces do corpo, da mente e do mundo. In: Arte e vida no séc. XXI: tecnologia, ciência e criatividade. Tradução de Flávia Gisele Saretta, São Paulo: UNESP, 2003, p. 26 .

CERTEAU, Michel de. A invenção do cotidiano. Tradução de Ephraim Ferreira Alves, 9a edição, Petrópolis: Vozes, 1994, p. 58.

Ver FOUCAULT, Michel. Estética: literatura e pintura, música e cinema Vol. III. Tradução de Inês Autran Dourado Barbosa, la edição, Rio de Janeiro: Forense Universitária, 2001, p. 279.

GUMBRECHT, Hans Ulrich. Modernização dos sentidos. Tradução de Lawrence Flores Pereira, la edição, São Paulo: 34, 1998, p. 285.

GADAMER, Hans-Georg. Culture and media. In: Cultural-political interventions in the unfinished project of enlightenment. London: MIT, 1992 , p. 177 .

Ibidem, p. 176-177.

GADAMER, Hans-Georg. Culture and media. In: Cultural-political interventions in the unfinished project of enlightenment. London: MIT, 1992, p. 177

Ibidem, p. 178

GADAMER, Hans-Georg. Culture and media. In: Cultural-political interventions in the unfinished project of enlightenment. London: MIT, 1992 , p. 184 .

Ibidem, p. 185

BENJAMIN, Walter. Obras escolhidas: magia e técnica, arte e política. Tradução de Sergio Paulo Rouanet, la edição, São Paulo: Brasiliense, 1994, p. 185 . 